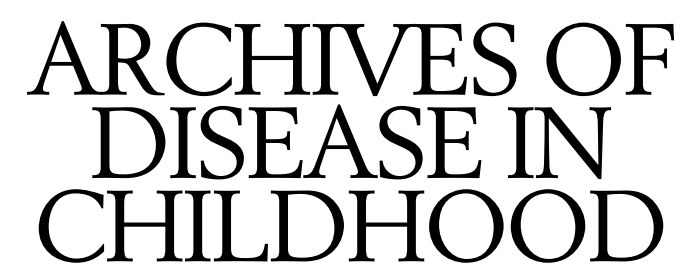

The Fournal of the Royal College of Paediatrics and Child Health

\title{
Annotation
}

\section{Gastrostomy feeding in the disabled child: when is an antireflux procedure required?}

Children with neurological impairment frequently exhibit clinical evidence of gastrointestinal dysmotility with oral motor impairment, gastro-oesophageal reflux (GOR), delayed gastric emptying, and constipation-for example, numerous reports have shown a high incidence of GOR $(15-75 \%)$ in neurologically impaired children. ${ }^{1-3}$ Recent studies using electrogastrography have suggested that vomiting in children with central nervous system disease involving the brainstem nuclei or regions next to the area postrema (the "vomiting centre") may result from a widespread disturbance of gastrointestinal motility (gastric dysrhythmia) or a persistent activation of the emetic reflex. ${ }^{4}$ Several reasons, in addition to the direct effect of central nervous system dysfunction on the lower oesophageal sphincter, have been proposed for the increased incidence of GOR in disabled children; these included hiatus hernia, adoption of a prolonged supine position, increased intra-abdominal pressure secondary to spasticity, scoliosis, or seizures. ${ }^{5}$ GOR is a significant clinical condition and is associated with reflux oesophagitis, recurrent vomiting, malnutrition, and recurrent aspiration pneumonia.

Feeding gastrostomy tubes are being used increasingly in this group of children in an attempt both to improve their nutritional status and to reduce the amount of time taken over feeding. Although long term follow up studies have shown that gastrostomy is an efficient and cost effective feeding technique, ${ }^{67}$ complications have been described in up to $26 \%$ of cases. ${ }^{8}$ One of the most significant complications is the development of GOR secondary to gastrostomy tube placement. ${ }^{90}$ Given that conventional medical treatment for GOR is often less effective in disabled children, this raises the question of whether a surgical antireflux procedure should routinely be performed at the same time as insertion of a gastrostomy tube.

Should an antireflux procedure be done at the time of gastrostomy?

Twenty years ago it was common practice for an antireflux operation to accompany the insertion of a feeding gastrostomy tube. ${ }^{29}$ The rationale for this being not only the high incidence of GOR in neurologically impaired children but also evidence that placement of a Stamm gastrostomy rendered the child prone to GOR, ${ }^{11}$ as well as the assumption that the increased volume of feeds made possible by the gastrostomy would promote latent GOR.

This attitude has changed over the past decade and the current view is that a routine antireflux procedure is not always necessary with a gastrostomy. This change has arisen for a number of reasons. First, the advent of the percutaneous endoscopic gastrostomy (PEG) made placement of a gastrostomy tube possible without laparotomy. Therefore the antireflux operation, which previously had been regarded as an adjunct to gastrostomy formation, became a separate major abdominal operation with significant morbidity. Second, there was evidence from an increasing number of centres that gastrostomy tube placement did not consistently promote GOR and, therefore, antireflux surgery was not essential in patients who did not have clinical evidence of GOR before gastrostomy. In 1988, Langer et al reported that of 50 patients who had gastrostomy alone, 22 (44\%) developed symptoms of GOR and 17 (34\%) required fundoplication. ${ }^{12}$ Subsequently, fundoplication rates of $14 \%$ and $4 \%$ in patients who had gastrostomy alone were reported by Wheatley and colleagues ${ }^{13}$ and Flake and colleagues, respectively. ${ }^{11}$ Third, there was increasing recognition of the significant morbidity associated with fundoplication.

Complications associated with fundoplication

The Nissen fundoplication, the most widely used procedure for controlling GOR, relieves symptoms in more than $80 \%$ of patients. ${ }^{1}$ However, in disabled patients in particular, this is at a cost of high morbidity and recurrence. Postoperative complications have been reported in up to $59 \%$ of patients. ${ }^{314}$ Pearl et al reviewed 234 patients following fundoplication, of whom 153 were disabled $^{15}$; the incidence of postoperative complications was $26 \%$ for disabled patients compared to $12 \%$ for normal children, and the reoperation rates were $19 \%$ and $5 \%$, respectively. Reported operative mortality rates for fundoplication range from $1-3 \%,{ }^{3}{ }^{14}$ and there is a significant late mortality related to co-existing abnormalities and intra-abdominal complications, notably adhesion, obstruction, and para-oesophageal hernia. ${ }^{16}$ Fundoplication, therefore has a significant risk of failure in neurologically impaired children, in addition to which there is a high risk of other complications developing.

The most frequent complication is recurrence of symptoms owing to herniation or failure of fundoplication wrap. ${ }^{17}$ This may occur days or years after the operation. Martinez et al found that more than $70 \%$ of neurologically impaired patients developed symptoms suggestive of recurrent GOR but in many patients these reflect oesophagogastric dysfunction. ${ }^{18}$ Objective evidence of recurrent reflux following Nissen fundoplication is reported in 6-36\% of patients. The incidence of repeat fundoplication ranges from 5-15\%. ${ }^{11} 161819$ Other complications that can accompany fundoplication include the gas-bloat syndrome, ${ }^{20}$ the dumping syndrome, ${ }^{121}$ and retching. ${ }^{22}$ The advent of laparoscopic fundoplication may have some favourable 
impact on postoperative morbidity associated with fundoplication but this has yet to be fully evaluated in children with neurological impairment.

\section{Delayed gastric emptying}

Another allied and controversial issue ${ }^{23}$ is when to perform a gastric emptying procedure in conjunction with an antireflux procedure. This is pertinent to the present discussion as there is evidence that, as delayed gastric emptying is common in neurologically impaired children with GOR, ${ }^{24}$ it affects the outcome of Nissen fundoplication in this group of children. ${ }^{25} 26$

\section{When is an antireflux procedure required?}

In attempting to answer this important clinical management question two issues arise. First, there is the problem of the accuracy of the diagnosis of GOR in disabled children. Although the gold standard for diagnosis of GOR is considered to be prolonged lower oesophageal $\mathrm{pH}$ monitoring, ${ }^{27}$ this can be unreliable in disabled children especially those with scoliosis in whom accurate positioning of the probe is more difficult. In Heine et al's study the sensitivity of an abnormal $\mathrm{pH}$ study as a predictor of oesophagitis, compared with the results of histological confirmation of GOR, was only $38.5 \%$, and the specificity was $71.4 \% .^{28}$ Nevertheless, in the light of available evidence it is clear that an antireflux procedure is required in all disabled children with severe GOR before gastrostomy and a number of reports testify to the value of oesophageal $\mathrm{pH}$ monitoring in selecting cases where such a procedure is indicated..$^{13}$ A value of $5 \%$ of a 24 hour period with $\mathrm{pH}<4$ in the lower oesophagus in a child older than 1 year is the accepted upper limit of normal, so an operational definition of severe GOR might be $>10 \%$ of a 24 hour period with a $\mathrm{pH}<4$ in the lower oesophagus.

As preoperative assessment for GOR may not predict which patients will develop GOR after gastrostomy some physicians recommend a clinical trial of nasogastric tube feeding for two weeks, and if this is tolerated without vomiting then the child is referred for PEG placement. The problem with this pragmatic approach, which is not based on the outcome of any clinical trials, is that GOR may develop some months after PEG replacement.

As mild GOR may not be exacerbated by PEG feeding, ${ }^{30} 31$ the second question is what degree of GOR is permissible before a trial of PEG feeding? Although there is very little evidence from prospective studies on which to base an opinion, in a child older than 1 year with mild to moderate GOR (5-10\% of a 24 hour period with $\mathrm{pH}<4$ in the lower oesophagus) given the consequences of major abdominal surgery and the potential complications of fundoplication, it is probably worth a trial of PEG feeding alone. Close follow up is required to monitor for the development of secondary GOR. In the event that GOR does occur, an attempt may be made to control symptoms using drug treatment (combinations of prokinetic agents, $\mathrm{H}_{2}$ antagonists or proton pump inhibitors) and a change from bolus feeding to continuous pump feeding. Secondary GOR in a disabled child fed via a PEG may be a temporary event accompanying, for instance, an intercurrent infection or deterioration in control of epilepsy, and standard antireflux measures may be enough to control the symptoms over the period of illness. If symptoms are not controlled medically then a repeat investigation of lower oesophageal $\mathrm{pH}$ may be required to determine the degree of severity of GOR, and the results may indicate the need for a fundoplication. Alternatives to fundoplication in those needing tube feeding but experiencing significant GOR include replacement of the PEG tube with a gastrojejunal feeding tube or surgical jejunostomy.
Research in this area is advancing rapidly as the nutritional needs of disabled children become more widely recognised. It is hoped that evidence from carefully conducted prospective studies will continue to throw light on the outstanding dilemmas surrounding the management of gastrostomy feeding in children with neurological impairment.

\section{PETER B SULLIVAN}

University of Oxford, Department of Paediatrics,

fohn Radcliffe Hospital, Oxford OX3 9DU, UK

1 Rice H, Seashore JH, Touloukian RJ. Evaluation of Nissen fundoplication in neurologically impaired children. $\mathcal{F}$ Pediatr Surg 1991;26:697-701.

2 Wesley JR, Coran AG, Sarahan TM, Klein MD, White SJ. The need for evaluation of gastroesophageal reflux in brain-damaged children referred for feeding gastrostomy. $\mathcal{Y}$ Pediatr Surg 1981;16:866-71.

3 Spitz L, Roth K, Kiely EM, Brereton RJ, Drake DP, Milla PJ. Operation for gastro-oesophageal reflux associated with severe mental retardation. Arch Dis Child 1993;68:347-51.

4 Ravelli AM, Milla PJ. Vomiting and gastroesophageal motor activity in children with disorders of the central nervous system. I Pediatr Gastroenterol Nutr 1998;26:56-63.

5 Halpern LM, Jolley SG, Johnson DG. Gastroesophageal reflux: a significant association with central nervous system disease in children. $\mathcal{F}$ Pediatr Surg 1991;26:171-3.

6 Rempel GR, Colwell SO, Nelson RP. Growth in children with cerebral palsy fed via gastrostomy. Pediatrics 1988;82:857-62.

7 Corwin DS, Isaacs JS, Georgeson KE, Bartolucci AA, Cloud HH, Craig CB. Weight and length increases in children after gastrostomy placement. $f \mathrm{Am}$ Diet Assoc 1996;96:874-9.

8 Marin OE, Glassman MS, Schoen BT, Caplan DB. Safety and efficacy of percutaneous endoscopic gastrostomy in children. Am f Gastroenterol 1994; 89:357-61.

9 Mollitt DL, Golladay ES, Seibert JJ. Symptomatic gastroesophageal reflux following gastrostomy in neurologically impaired patients. Pediatrics 1985; 75:1124-6.

10 Grunow JE, al-Hafidh A, Tunell WP. Gastroesophageal reflux following percutaneous endoscopic gastrostomy in children. F Pediatr Surg 1989;24:42-4.

11 Flake AW, Shopene C, Ziegler MM. Anti-reflux gastrointestinal surgery in the neurologically handicapped child. Pediatr Surg Int 1991;6:92-4.

12 Langer JC, Wesson DE, Ein SH, et al. Feeding gastrostomy in neurologically impaired children: is an antireflux procedure necessary? $\mathcal{F}$ Pediatr Gastroenterol Nutr 1988;7:837-41.

13 Wheatley MJ, Wesley JR, Tkach DM, Coran AG. Long-term follow-up of brain-damaged children requiring feeding gastrostomy: should an antireflux procedure always be performed? F Pediatr Surg 1991;26:301-4.

14 Dedinsky GK, Vane DW, Black T, Turner MK, West KW, Grosfeld JL. Complications and reoperation after Nissen fundoplication in childhood. Am ₹ Surg 1987;153:177-83.

15 Pearl RH, Robie DK, Ein SH, et al. Complications of gastroesophageal antireflux surgery in neurologically impaired versus neurologically normal children. F Pediatr Surg 1990;25:1169-73.

16 Smith CD, Othersen HB Jr, Gogan NJ, Walker JD. Nissen fundoplication in children with profound neurologic disability. High risks and unmet goals. Ann Surg 1992;215:654-8.

17 Kimber C, Kiely EM, Spitz L. The failure rate of surgery for gastro-oesophageal reflux. F Pediatr Surg 1998;33:64-6.

18 Martinez DA, Ginn-Pease ME, Caniano DA. Recognition of recurrent gastroesophageal reflux following antireflux surgery in the neurologically disabled child: high index of suspicion and definitive evaluation. F Pediatr Surg 1992;27:983-8.

19 Wheatley MJ, Coran AG, Wesley JR, Oldham KT, Turnage RH. Redo fundoplication in infants and children with recurrent gastroesophageal reflux. f Pediatr Surg 1991;26:758-61.

20 Moulis H, Vender RJ. Percutaneous endoscopic gastrostomy for treatment of gas-bloat syndrome. Gastrointest Endosc 1993;39:581-3.

21 Samuk I, Afriat R, Horne T, Bistritzer T, Barr J, Vinograd I. Dumping syndrome following Nissen fundoplication; diagnosis and treatment. $\mathcal{F}$ Pediatr Gastroenterol Nutr 1996;23:235-40.

22 Borowitz SM, Borowitz KC. Oral dysfunction following Nissen fundoplication. Dysphagia 1992;7:234-7.

23 Maxson RT, Harp S, Jackson RJ, Smith SD, Wagner CW. Delayed gastric emptying in neurologically impaired children with gastroesophageal reflux: the role of pyloroplasty. F Pediatr Surg 1994;29:726-9.

24 Papaila JG, Wilmot D, Grosfeld JL, Rescorla FJ, West KW, Vane DW. Increased incidence of delayed gastric emptying in children with gastroesophageal reflux. A prospective evaluation. Arch Surg 1989;124:933-6.

25 Fonkalsrud EW, Ellis DG, Shaw A, et al. A combined hospital experience with fundoplication and gastric emptying procedure for gastroesophageal reflux in children. 7 Am Coll Surg 1995;180:449-55.

26 Alexander F, Wyllie R, Jirousek K, Secic M, Porvasnik S. Delayed gastric emptying affects outcome of Nissen fundoplication in neurologically impaired children. Surgery 1997;122:690-8.

27 A standardized protocol for the methodology of esophageal $\mathrm{pH}$ monitoring and interpretation of the data for the diagnosis of gastroesophageal reflux. Working Group of the European Society of Pediatric Gastroenterology and Nutrition. F Pediatr Gastroenterol Nutr 1992;14:467-71.

28 Heine RG, Reddihough DS, Catto-Smith AG. Gastro-oesophageal reflux and feeding problems after gastrostomy in children with severe neurological impairment. Dev Med Child Neurol 1995;37:320-9.

29 Sulaeman E, Udall JN Jr, Brown RF, et al. Gastroesophageal reflux and Nissen fundoplication following percutaneous endoscopic gastrostomy in children. F Pediatr Gastroenterol Nutr 1998;26:269-73

30 Launay V, Gottrand F, Turck D, Michaud L, Ategbo S, Farriaux JP. Percutaneous endoscopic gastrostomy in children: influence on gastroesophageal taneous endoscopic gastrostomy in

31 Isch JA, Rescorla FJ, Scherer LR, West KW, Grosfeld JL. The development of gastroesophageal reflux after percutaneous endoscopic gastrostomy. $\mathcal{F}$ Pediatr Surg 1997;32:321-3. 